carcinogens. He too has used bronze maggots over several years.

The youth and lack of history suggestive of genetic predisposition in these patients would seem to constitute further evidence for banning the use of chrysoidine for angling, at least until more conclusive studies have been performed.

J A Massey

R C L FENELEY P H ABRAMS

\author{
Ham Green Hospital,
Bristol BS20 0HW \\ 1 Garner RC, Nutman CA. Testing of some azo dyes \\ and their reduction products for mutagenecit \\ using Salmonella typhimurium TA 1538. Mutat
}

SIR,-Mr G M Sole raises the possibility of a genetic predisposition to bladder cancer (20 October, p 1043). An answer may be found in the $\mathrm{N}$-acetyltransferase phenotype status of the two brothers. Populations of slow and fast acetylators have been identified and an association between transitional cell bladder cancer and slow acetylation established. ${ }^{12}$ Slow acetylation is an autosomal recessive phenotype which may have been inherited by both brothers with a resultant increased risk from their exposure to smoking and chrysoidine.

Department of Urology,
St Mary's Hospital,

1 Cartwright RA, Glashan RW, Rogers HJ, et al. Role of $N$-acetyltransferase phenotypes in bladde carcinogenesis: a pharmacokinetic epidemiologica 2 Evans DAP, Eze LC, Whibley EJ. The association of the slow acetylator phenotype with bladder cancer. the Med Genet 1983;20:330-3.
f

\section{Plasma exchange in rapidly progressive crescentic glomerulonephritis}

SIR,-We were interested in Dr Terry Hamblin's comments on the problems of using randomised controlled trials to study the effectiveness of plasma exchange in treating rapidly progressive crescentic glomerulonephritis (29 September, p 779). Our own study was affected by operational difficulties in that plasma exchange was not always fully available and we felt that such aggressive treatment should be started as soon as possible after biopsy diagnosis. ${ }^{1}$ Intravenous pulses of methylprednisolone can be given at any time of the day or night and are cheaper and easier to administer than plasma exchange and so tended to be used when trained medical staff were in short supply-for example, during weekends or holidays. However, weekends, holidays, staff promotion, or sickness tend to be random variables themselves or, if regularly recurring, of little pathogenic significance.

From 1977 to 1981, 27 patients on Merseyside with rapidly progressive crescentic glomerulonephritis were treated either with plasma exchange (13) or pulse methylprednisolone (14) depending on the availability of the former and the balance within the series. All patients also received oral prednisolone and azathioprine or cyclophosphamide. The two groups were well matched for factors affecting prognosis such as age, severity of disease, and incidence of associated disorders such as polyarteritis nodosa. Both treatments were equally effective in reversing progression into renal failure: 7 patients given plasma exchange and 11 patients given pulse methylprednisolone responded promptly within one month of starting treatment.
This was in striking contrast to an earlier series of 17 comparable patients treated in Liverpool from 1972 to 1979 with oral therapy alone, when only one patient responded. In consequence we no longer use plasma exchange routinely in rapidly progressive crescentic glomerulonephritis mediated by immune complexes, and all patients are given pulse methylprednisolone.

Further anaiysis of the responding patients showed that the follow up dose of oral steroids may be critical in at least the first six months. ${ }^{2}$ In patients whose renal function remained stable the dose of prednisolone was reduced from $30 \mathrm{mg}$ daily after six to eight weeks to $15-20 \mathrm{mg}$ at three months, 10-15 mg at six months, and 5-10 mg after one year. In patients who relapsed doses of prednisolone had been reduced more rapidly. Some patients seemed sensitive to a reduction in dose even after two years.

Great care therefore needs to be taken, especially for patients with signs of residual disease and for whom replacement therapy would be difficult. Indeed these patients may need to take both prednisolone and azathioprine indefinitely in maintenance doses similar to those used for patients with stable renal allografts and systemic lupus erythematosus. Fortunately such treatment is well tolerated, and serious side effects are rare.

J M BONE

Regional Renal Unit,

Royal Liverpool Hospital,

South Cleveland Hospital

Middlesbrough, Cleveland

1 Stevens ME, McConnell M, Bone JM. Aggressive treatment with pulse methylprednisolone or plasma exchange is justified in rapidly progressive glomerulonephritis. Proc Eur Dial Transplant Assoc
1982;19:724-31. Stevens ME Bone

dosage dosage in rapidly progressive crescentic glomerulone-
phritis (RPCGN) successfully treated with pulse phritis (RPCGN) successfully treated with pulse (Px). Proc Eur Dial Transplant Assoc (in press).

\section{Algorithm for modified alkaline} diuresis in salicylate poisoning

SIR,-The algorithm for treating salicylate poisoning suggested by Dr I J Gordon and others (20 October, p 1039) gives guidelines on treatment when serum salicylate concentrations are $500-800 \mathrm{mg} / \mathrm{l}$. The alkalinising regimen they describe was not used therapeutically for more severe poisoning. We describe a 52 year old woman who took three separate overdoses of aspirin. These allowed us to compare three different treatments. On each occasion the patient had gastric lavage and activated charcoal.

The first overdose produced a serum salicylate concentration of $790 \mathrm{mg} / 1$ five and a quarter hours after ingestion. Treatment was by forced simple diuresis (urine output of $5120 \mathrm{ml}$ over 14 hours, urine $\mathrm{pH} \leqslant 6$ throughout). The serum salicylate concentration fell with a half life of 24 hours.

Two weeks later another overdose produced a serum salicylate value of $830 \mathrm{mg} / \mathrm{l}$ nine and a half hours after ingestion. Initial treatment was by forced simple diuresis (urine output $7966 \mathrm{ml}$ over 15 hours, urine $\mathrm{pH} \leqslant 6$ ), but after 15 hours' treatment the serum salicylate concentration was still $800 \mathrm{mg} / \mathrm{l}$ and fluid overload had occurred. Treatment was changed to an alkalinising regimen (652 mmol(mEq) bicarbonate over 16 hours), and diuretics were given. This produced a diuresis of $5430 \mathrm{ml}$ of urine over 16 hours. The alkalinising regimen did not alter the urine $\mathrm{pH}$ during the initial 10 hours of the regimen (although blood $\mathrm{pH}$ rose to $7 \cdot 56$ ), and the serum salicylate half life remained 24 hours. The final six hours of the regimen produced a urine $\mathrm{pH}$ of 8 , however, with successful salicylate clearance (serum half life eight hours).
The serum salicylate concentration was $630 \mathrm{mg} / \mathrm{l}$ when urinary alkalinisation was achieved.

Two months later another overdose produced a serum salicylate concentration of $840 \mathrm{mg} / 1$ seven and a half hours after ingestion. On the modified alkaline diuresis method of Dr Gordon and his colleagues blood $\mathrm{pH}$ rose to 7.6 but urinary $\mathrm{pH}$ remained $\leqslant 6$. Serum salicylate fell with a half life of 25 hours. Electrolyte values were normal at presentation, except bicarbonate $(15 \mathrm{mmol} / \mathrm{l})$, but the potassium concentration rose to $6.6 \mathrm{mmol}$ $(\mathrm{mEq}) / \mathrm{l}$ and urea to $12.6 \mathrm{mmol} / \mathrm{l}(76 \mathrm{mg} / 100 \mathrm{ml})$ two hours after the start of the alkalinising regimen. Potassium was excluded from the regimen and six hours later the serum potassium concentration had fallen to $2.8 \mathrm{mmol} / \mathrm{l}$.

Urinary clearance of salicylate is related to urinary $\mathrm{pH} .{ }^{1}$ In severely poisoned patients it is not always possible to alkalinise the urine with the regimen described. Rapid changes in potassium concentration may occur in patients treated with alkalinisation. It is unclear whether these electrolyte changes are more dangerous than the salicylate itself. We believe that neither forced alkaline diuresis nor modified alkaline diuresis is entirely satisfactory in severe $(\geqslant 790 \mathrm{mg} / \mathrm{l})$ salicylate poisoning.

$S$ W COPPACK C S Higgens

Queen Mary's Hospital,
London SW15 5PN 1 Prescott LF, Balali-Wood M, Critchley JAJH,
Johnson AF, Proudfoot AT. Diuresis or urinary
alkalinisation for salicylate poisoning. $\mathrm{Br} M$ Med $\mathcal{F}$ 1982;285:1383-6.

Failure of the cervical cytology screening programme

SIR,-Cervical cytology is in the news. September and October have seen a flurry of articles in the $B M \mathcal{H}$, the Lancet, and the Fournal of the Royal College of General Practitioners. The DHSS has also recently issued its latest advice on cervical screening based on the report of the committee on gynaecological cytology. Unfortunately the advice from the DHSS, the message from the recent papers, and the general private undercurrents from those working in cytology about what would be an appropriate policy fail to tally.

Official policy continues to recommend smears $(a)$ at five year intervals for women aged 35 and over, (b) for women who have been pregnant three or more times, and $(c)$ after every pregnancy. For younger women the new recommendation is a cervical smear when the woman first presents for contraception and thereafter at ages 20,25, etc, and not at intervening ages. Although an attempt has been made to simplify the previous muddled recommendations issued by the DHSS, there are still inconsistencies. For example, the DHSS attempts to reduce the number of what it sees as unnecessary smears being taken in the young age groups but then recommends that smears should be taken when women first present for contraception. Surely it would be sensible to add the rider "within the first two years of being sexually active," as it seems unnecessary to take a cervical smear from someone who has never been sexually active or who has just started having intercourse.

Current wisdom also has it that the wrong women-that is, young women-are the ones getting smears but not the cancer, whereas older women are getting the cancer but not the smears. Data support this to a certain extent, but, although most cases of cervical cancer 
occur in older women, there is a marked increase in the incidence of cancer among those aged under 35, in whom most smears are actually done.

As has been stated by some experts, cervical screening may be assumed simply to be holding in check a much larger potential increase in the incidence of invasive cancer in this young age group, possibly due to increased sexual activity. Epidemiological good sense might suggest continuing to perform frequent smears in this group and at that same time increasing smear rates in older women rather than decreasing the smear rates in the young and increasing the rate in older women.

Perhaps the sentence which sums up the present position best is in the leading article on failures of the cervical screening programme by Dr Jocelyn Chamberlain (6 October, p 853): "The principal reason for choosing five year screening intervals is cost." Given that with all screening programmes there is a delicate balance between cost and effectiveness it is time we told our patients that it is purely on grounds of cost rather than of efficacy that the DHSS is recommending a five year rather than a three year interval.

For the cervical screening programme to be more effective the primary health care system has to organise itself to take the smears, and the time interval at which they are taken must be seen to be appropriate both by people implementing the service and by the women who are screened. Why therefore is a five year interval being publicly advised at the moment, when privately three years is being advocated?

Oxford OX1 2NA

ANN MCPHERSON

SiR,-The many letters (3 November, $p$ 1223) in response to your leading article and papers on this subject (6 October, p 853, 883, 891, $894)$ reflect the range of practices and concerns that have developed in the cervical cytology screening programme in Britain. As one who was on the central advisory committee on gynaecological cytology for a dozen years, where strong representation was made to establish and organise a pattern of control of our then developing resources, I can identify the causes of failure.

Firstly, some 15 years ago we were assured that instead of a comprehensive countrywide coverage by cancer registries, which some other national screening programmes have successfully used, we were to use the computerised age-sex registers being developed in family practitioner committees, which then cope with all preventive health measures. The tardiness of this development, even when family practitioner committees were made conterminous with area health authorities in 1974, was a basic fault, and only recently has some improvement occurred. The Exeter family practitioner service computer unit states that by the end of next year nearly half of the population should be recorded on family practitioner committee computers.

It has been characteristic of Britain's approach to such problems to allow a great degree of licence to individual health authorities, which has resulted in very patchy progress. Now as a result of a significant increase in the incidence of cervical cancer in the young there is a further danger of a multiplicity of computer systems being introduced. There call system of the family practitioner committee must dovetail into the system for repeat requests of the health authority laboratories. There is a further complication in the conurbations, where the number of attenders at clinics from other districts may be four or five times that of those from the local population. This again argues for uniformity of practice and computer systems.
Dr Carolyn D Ritchie and Miss Patricia Last (p 1224) mention the loss to follow up of many of their patients. We have ourselves run a manual laboratory repeat request system for over 20 years for a subregional service; one analysis showed that we were getting about $93 \%$ compliance from GPs and clinic doctors in controlling such cases through maintaining a simple diary list and sending follow up letters, on which we type the previous test report (an important factor in the reminder) and allowing space at the bottom of the form for a simple handwritten reply. Dedicated staff and a good rapport with GPs and clinic staff make such results possible.

The idea of a personal record card is another valuable adjunct. This idea was tried out 10 to 15 years ago by Dr MacIntyre of Leeds, who found that many were lost over the space of a few years. I believe with Dr M C D Heath that the method should be tried again as people are now more receptive to such forms of control and it would avoid unnecessary duplication of smears.

Perhaps we should recreate the coordinating committees that were developed early in the screening service. They brought together gynaecologists, cytopathologists, general practitioners, public health officers, and family practitioner representatives as well as the voluntary organisations to make sure that a comprehensive service was provided, creating effective cooperation and identifying target norms.

There is an urgent need for a central pronouncement on the best way to present a coordinated attack on a problem that, after many years and at much cost, we have failed to tackle as successfully as other countries.

Regional Cytology Centre, St Stephen's Hospital,

O A N Husain

SIR,-The leading article by Dr Jocelyn Chamberlain, the report from the Imperial Cancer Research Fund Coordinating Committee on Cervical Screening, and the article by Professor J M Ellwood and others highlight the deficiencies of the British cytology screening service. The time has come for a complete rethink. Too many unnecessary smears are taken.

In countries such as those in Scandinavia, where screening is systematic and based on population registers, there has been a fall in the incidence of and mortality from cervical cancer. The ICRFCC paper proposes a system based on family practitioner committee lists and Dr Philips (3 November) describes this even more succinctly.

Family practitioner committee (primary care in Scotland) computers are designed to keep names of patients registered with individual GPs so that the doctors may be remunerated correctly. Ninety eight per cent of women are registered with general practitioners, so for the first time all women can be identified. Screening at regular intervals based on call and recall from these names need be the only source of smears. The women would be notified and given an appointment. Payment should be made for these routine smears from women of all ages. Most GPs now have ancillary staff, who can help them ensure the attendance of the most vulnerable the sexually active women. A copy of the normal smear reports could go directly to the family practitioner committee so that GPs could be saved considerable form filling.

Smears need no longer be taken at family planning or antenatal or postnatal clinics.
Incidental smears taken by gynaecologists because of symptoms would not be regarded as screening smears. A recall system for all patients with abnormal smears should clearly be the responsibility of the reporting laboratory, which could use the family practitioner committee facilities for tracing patients. The laboratory files could be manual (Dr C Pike, 3 November, p 1224) or on a microcomputer. The interval between smears should be decided in line with current research.

J Elizabeth MaCgregor Department of Pathology, University of Aberdeen

SIR,-Having recently discussed the articles on cervical screening at our journal club, we feel the problems are the same as those summarised at the end of the British Society for Clinical Cytology pamphlet of 1981: "Women who are now dying from cervical cancer are those who have never had a smear." As the main obstacle seems to be in offering access to the screening programme to those who may never have even contemplated such an investigation, would it not be appropriate to encourage the drug companies and firms making associated products, such as oral contraceptives and tampons, to carry a health advisory note to try to bridge this gap-for example, "It is every woman's right to have a cervical smear-they save lives. Have you had one in the past five years ?" We feel that such a notice could only improve the current situation of needless deaths in an unscreened population.

JOHN OSBORNE KEITH EDMONDS FRANK LOEFFLER

Queen Charlotte's Maternity Hospital,
London W6 OXG

\section{Colposcopy in a district general hospital}

SIR,-Without wishing to detract from the article by Dr Albert Singer and his colleagues (20 October, p 1049), I must say that their concluding section on costs is weak and misleading. They state, "Once the capital outlay for equipment has been made there are substantial savings for the district general hospital in the introduction of a colposcopy clinic." The substantial savings appear to refer to the average costs of traditional inpatient treatment - that is, cone biopsy under general anaesthesia. Because average cost includes overheads it is not a realisable financial saving. Whether or not such patients are admitted, staff salaries must be paid and wards heated, lit, and cleaned. Thus the only real saving is the marginal cost of treating such women as inpatients - that is, the additional cost of stationery, food, drugs, etc, associated with such admissions. Of course, if the reduction in the inpatient load is large enough to allow, say, a ward to be closed then a substantial saving will be realisable. This is unlikely to occur in practice as such "empty" beds would tend to be used to admit patients on waiting lists for elective surgery.

I agree with Dr Singer and his colleagues that a colposcopic service should be widely available to all women with abnormal cervical smears. It would appear to be much more socially efficient than traditional inpatient treatment, but the associated "substantial 